\title{
Cohort Profile: The Danish Testicular Cancer Late Treatment Effects Cohort (DaTeCa-LATE)
}

\author{
Michael Kreiberg ${ }^{1 *}$, Mikkel Bandak ${ }^{1}$, Jakob Lauritsen ${ }^{1}$, Julie Wang Skøtt', \\ Nanna Borup Johansen ${ }^{2}$, Mads Agerbaek ${ }^{3}$, Niels Vilstrup Holm ${ }^{4}$, Christoffer Johansen ${ }^{1,5}$ \\ and Gedske Daugaard ${ }^{1}$
}

${ }^{1}$ Department of Oncology 5073, Copenhagen University Hospital, Rigshospitalet, Copenhagen, Denmark, ${ }^{2}$ Research Centre for Prevention and Health, Centre for Health, Glostrup, Denmark, ${ }^{3}$ Department of Oncology, Aarhus University Hospital, Aarhus, Denmark, ${ }^{4}$ Department of Oncology, Odense University Hospital, Odense, Denmark, ${ }^{5}$ Unit of Survivorship, Danish Cancer Society Research Center, Danish Cancer Society, Copenhagen, Denmark

The cohort was set up in order to analyze late effects in long-term testicular cancer survivors (TCS) and to contribute to the design of future follow-up programs addressing and potentially preventing late effects. Data for this cross-sectional study were collected between January 1, 2014, and December 31, 2016, among living Danish TCS and 60\% agreed to participate in the cohort $(N=2,572)$. Mean time since testicular cancer (TC) diagnosis was 18 years (range 7-33) and mean age of participants was 53 years (range 25-95). Data consist of results of a questionnaire with patient reported outcomes which covers a broad range of items on late-effects. The study also included data obtained through linkages to Danish registries, a biobank, and clinical data from hospital files and pathology reports originating from the Danish Testicular Cancer Database (DaTeCa). The treatment during the observation period has been nearly the same for all stages of TC and is in agreement with today's standard treatment, this allows for interesting analysis with a wide timespan. We have extensive data on non-responders and are able to validate our study findings. Data from a Danish reference population $(N=162,283)$ allow us to compare our findings with a Danish background population. The cohort can easily be extended to access more outcomes, or include new TCS. A limitation of the present study is the cross-sectional design and despite the large sample size, The Danish Testicular Cancer Late Treatment Effects Cohort (DaTeCa-LATE) lacks statistical power to study very rare late effects. Since it was voluntary to participate in the study we have some selection bias, for instance, we lack responders who were not in a paired relationship, but we would still argue that this cohort of TCSs is representative for TCSs in Denmark.

Collaboration and data access: Researches interested in collaboration with the DaTeCa-LATE study group please contact Professor Gedske Daugaard kirsten.gedske. daugaard@regionh.dk.

Keywords: testicular cancer, germ cell cancer, cohort profile, cohort study, cancer late effects, late effects

\section{INTRODUCTION - WHY WAS THE COHORT SET UP?}

In industrialized countries, testicular cancer (TC) is the most common solid tumor in men between 20 and 40 years of age. In Denmark, the age standardized incidence rate per 100,000 person-years is 9.9 which corresponds to 300 incident cases annually $(1,2)$. TC is a highly curable tumor with a 5 -year survival of $95-98 \%$, which results in an increased population of long-term testicular cancer 
survivors (TCS). However, treatment is hampered by late effects, including increased risk for secondary cancer $(3,4)$, metabolic syndrome (5), cardiovascular disease (6), neurotoxicity (7), sexual dysfunction (8), and psychosocial problems (9). Nevertheless, our current knowledge of risk factors, the related health problems and the quality of the posttreatment life remains insufficient to fully optimize individual programs designed to address and reduce long-term toxicity and improve quality of life in TC survivors.

Historically there have been small variations in standard TC treatment in Denmark, and now it is completely harmonized in national multidisciplinary guidelines for treatment and follow-up carried out at three university hospitals responsible for this patient group. The treatment algorithm is as follows: (a) patients with disease confined to one or both testicles (stage I disease) are treated with orchiectomy followed by surveillance, and approximately $75 \%$ of stage I patients are cured by this treatment alone $(10,11)$; (b) patients with seminoma histology and limited retroperitoneal disease are offered treatment with radiotherapy (RT) or chemotherapy; (c) in the remaining patients with disseminated disease, chemotherapy with three or four courses of bleomycin, etoposide, and cisplatin (BEP) is the treatment of choice depending on prognostic group; and (d) a minority of patients, approximately $5 \%$, will need more than one line of treatment (MTOL) due to progressive disease or disease relapse.

In order to clarify late effects related to treatment, apart from orchiectomy, we have chosen, where appropriate, to use the surveillance group (stage I TC) as a reference group.

The Danish Testicular Cancer Late Treatment Effects Cohort (DaTeCa-LATE) consists of a combination of data derived from the clinical database DaTeCa (1984-2007) (11), national health and sociodemographic registries (1977-2016), a biobank with blood and sputum samples, and an 167-item questionnaire containing patient reported outcome measures (PROMs) obtained in 2014-2016. The cohort design is illustrated in Figure 1.
The cohort was set up in order to analyze treatment-related late effects in TCS and to contribute to the design of future followup programs addressing and potentially preventing late effects in long-term TCS.

The Danish Testicular Cancer Late Treatment Effects Cohort is a nationwide and population-based cohort and is located at the Department of Oncology, Rigshospitalet, Copenhagen University Hospital, Denmark.

\section{WHO IS IN THE COHORT?}

In 2014, we accessed the DaTeCa database, which at that time included some 7,500 TC patients. Patients in the database have been identified through the Danish Cancer Register and hospital files. In the present study, we included 5,367 of these patients treated in the period between January 1, 1984, and December 31, 2007, as we aimed for a long observational period facilitating the study of late effects. The mean time since diagnosis is 18 years (range 7-33). Inclusion criteria in the DaTeCa database covers the diagnosis of a germ cell cancer (International Classification of Diseases, 10th revision, ICD10: DC 62.1-62.9, DC38.3, and DC48.0, the latter two together with germ cell histology), Danish citizenship, follow-up and medical treatment conducted at an oncology ward in Denmark. The overall coverage in the database is approximately $80 \%$ (11). In the DaTeCa database, we identified a total of 4,271 TCS eligible for participation in DaTeCa-LATE. The main reasons for exclusion of patients $(N=1,096)$ are presented in the flowchart (Figure 2).

A postal invitation to participate was sent out to all eligible TCS in November 2014. Following written informed consent, patients filled in a questionnaire either in a paper version or electronically. Reminder postal invitations were sent out to nonresponders and non-responders were also reached by phone.

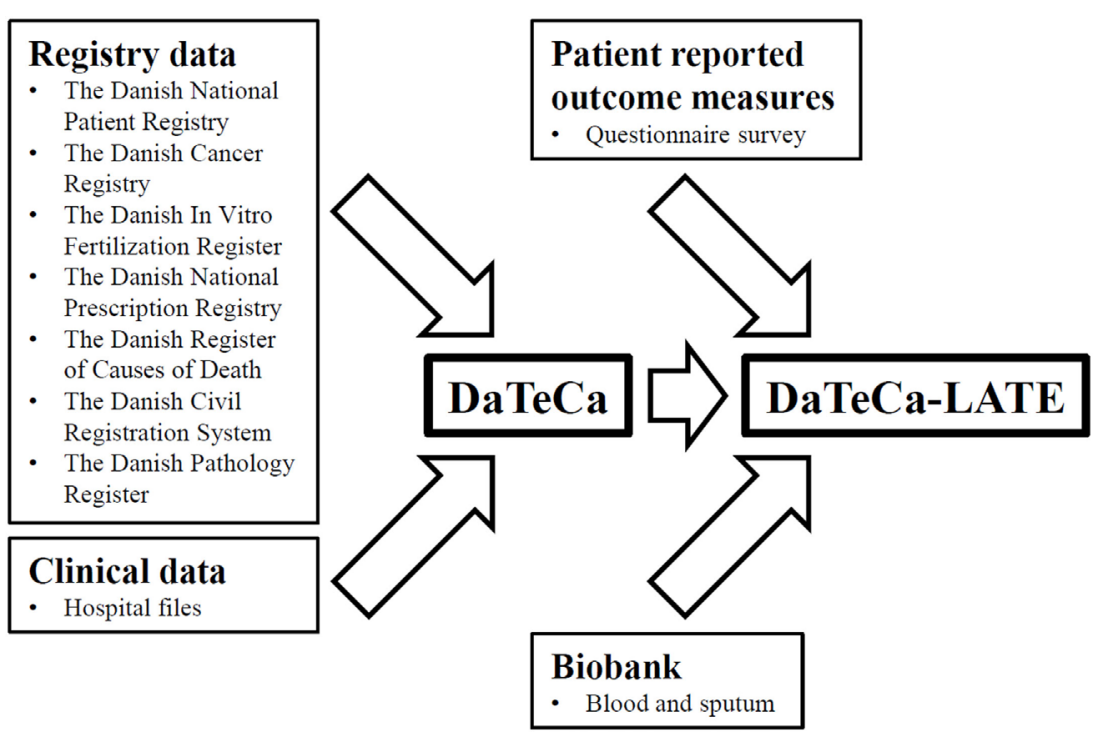

FIGURE 1 | The Danish Testicular Cancer Late Treatment Effects Cohort (DaTeCa-LATE) cohort design. 


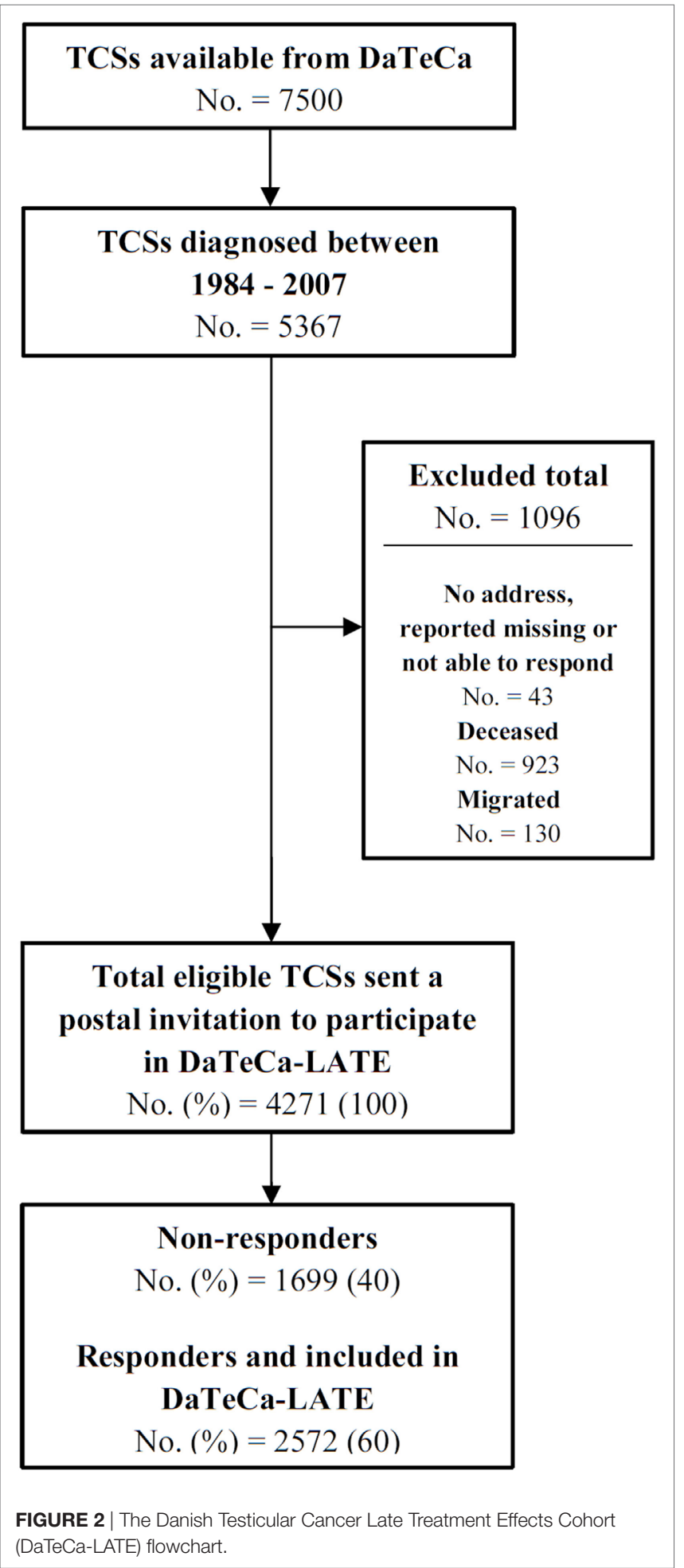

By December 31, 2016, a total of 2,572 (60\%) of questionnaires distributed was filled in and returned, and this number of TCS make up the DaTeCa-LATE study population.

Data on TCS non-responders were collected from the DaTeCa database and Danish registries for comparison with responders. As illustrated in Table 1 responders were younger at time of
TABLE 1 | Characteristics of responders included in DaTeCa-LATE and non-responders.

\begin{tabular}{|c|c|c|c|}
\hline Characteristics & $\begin{array}{c}\text { Responders, } \\
\text { no. (\%) } 2,572(60)\end{array}$ & $\begin{array}{l}\text { Non-responders, } \\
\text { no. }(\%) 1,699(40)\end{array}$ & $P$-Value \\
\hline Age treatment (years) & & & $<0.001$ \\
\hline Mean & 35 & 34 & \\
\hline $\mathrm{SD}$ & 10 & 9 & \\
\hline Age attained (years) & & & $<0.001$ \\
\hline Mean & 53 & 52 & \\
\hline SD & 11 & 11 & \\
\hline Time since diagnosis (years) & & & 0.014 \\
\hline Mean & 18 & 17 & \\
\hline SD & 7 & 7 & \\
\hline Decade of treatment, no. (\%) & & & 0.051 \\
\hline $1980 s$ & $514(20)$ & $289(17)$ & \\
\hline 1990s & $1,126(44)$ & $773(46)$ & \\
\hline 2000s & 932 (36) & $637(37)$ & \\
\hline Treatment, no. (\%) & & & $<0.001$ \\
\hline Surveillance & $1,174(46)$ & $947(56)$ & \\
\hline BEP & $896(35)$ & $441(26)$ & \\
\hline $\mathrm{RT}$ & $323(12)$ & $236(14)$ & \\
\hline MTOL & $85(3)$ & $27(1)$ & \\
\hline Othera & $94(4)$ & $48(3)$ & \\
\hline Histology, no. (\%) & & & 0.384 \\
\hline Seminoma & $1,370(53)$ & $935(55)$ & \\
\hline Nonseminoma & $1,201(47)$ & $764(45)$ & \\
\hline Comorbidity, no. (\%) & & & 0.190 \\
\hline No comorbidity & 2,207 (86) & $1,424(84)$ & \\
\hline One or more comorbidities & $365(14)$ & 275 (16) & \\
\hline Place of living, no. (\%) & & & 0.444 \\
\hline Urban & 857 (33) & 547 (32) & \\
\hline Rural & $1,715(67)$ & $1,152(68)$ & \\
\hline Marital status, no. (\%) & & & $<0.001$ \\
\hline Paired relation & $1,697(66)$ & $911(54)$ & \\
\hline $\begin{array}{l}\text { Single, separated, } \\
\text { divorced, widower }\end{array}$ & $875(34)$ & $788(46)$ & \\
\hline
\end{tabular}

Age treatment, age attained. and time since diagnosis were compared with independent t-test. Column proportions were compared through chi-squared analysis. a Metachronous and synchronous.

${ }^{b}$ Extragonadal primary $(N=123)$.

BEP, bleomycin, etoposide, cisplatin; RT, radiotherapy; MTOL, more than one line of treatment.

treatment ( 34 vs. 35 years) and attained age ( 52 vs. 53 years) than non-responders $(P<0.001)$.

The response rate was dependent on treatment modality. As such, the response rate was $55 \%$ in TCS followed on a surveillance program, $67 \%$ in TCS treated with BEP, $58 \%$ in TCS treated with RT, and $76 \%$ in TCS treated with MTOL. These data suggest that more intensive treatment lead to a higher response rate. Another difference observed, concerns marital status. TCS living in a paired relation had a response rate of $66 \%$ compared to men who were single, separated, divorced, or widowed with a response rate of $54 \%(P<0.001)$. No difference between responders and non-responders were observed concerning decade of treatment, histology of the tumor, comorbidity at time of filling in the questionnaire and place of living.

As a reference population we use data obtained from the Danish National Health Profile survey from 2013 based on five regional stratified random samples and one national random sample. A total of 300450 individuals, aged 16 or older, were invited to participate with a response rate of 54\% (162,283 individuals) (12). As many of the outcomes in the Danish National Health Profile 
survey are the same as in DaTeCa-LATE this allows for a straightforward comparison with the reference population, concerning the following demographic variables and outcomes: alcohol consumption, smoking, education, age, self-rated health, physical activity, perceived stress, physical function, and body mass index.

In the present study, continuous variables were compared with independent $t$-tests while column proportions were compared with chi-squared analysis. Statistical analyses were performed by using SPSS 22.0 (SPSS, Chicago, IL, USA).

The regional ethical committee of the Capital Region of Denmark approved the study (file number, H-2-2012-044).

The collection and use of questionnaire data from the reference population were approved by the five regional data protection agencies.

This report covers cross-sectional data obtained at December 31,2016 , only.

\section{WHAT HAS BEEN MEASURED?}

Variables in DaTeCa-LATE were chosen based on literature describing late effects in TCS together with clinical experiences concerning late effects in cancer patients. Table 2 gives an overview on variables in DaTeCa-LATE in addition to the variables originating from the DaTeCa database.

\section{HOSPITAL FILES AND PATHOLOGY REPORTS}

Clinical data in DaTeCa-LATE are obtained from hospital files and pathology reports and are available from the DaTeCa database (11), and depending on stage and treatment, more than 300 variables are available covering histology, stage, tumor markers, treatment, relapses, kidney function, and lung function.

\section{DANISH REGISTRIES}

Since April 1968, every Danish resident has been assigned a unique civil personal 10-digit registration number. Each individual is identified with this number and it can be linked to different health-related and sociodemographic registries.

Seven different Danish national registries have for now contributed to DaTeCa-LATE. From the Civil Registration System (13), we retrieved the dates of migration and cohabitation status, information on comorbidity were collected using The National Patient Registry (14), and The Danish Cancer Registry provided information on cancer diagnosis in order to identify the patients (15). Combining hospital files including pathology reports and data from the Danish Pathology Register data on tumor characteristics were obtained (16).

TABLE 2 | Outcomes measured in DaTeCa and DaTeCa-LATE surveys.

\begin{tabular}{|c|c|c|}
\hline \multicolumn{2}{|l|}{ Sources } & \multirow[t]{2}{*}{ Outcomes } \\
\hline \multicolumn{2}{|l|}{ DaTeCa } & \\
\hline \multicolumn{3}{|l|}{ Clinical data } \\
\hline 1984-2015 & Hospital files & $\begin{array}{l}\text { Stage (prognostic group, metastatic site), treatment, relapses, kidney function, } \\
\text { lung function, pathology reports, ototoxicity, neurotoxicity, smoking at diagnosis }\end{array}$ \\
\hline \multicolumn{3}{|c|}{ Registry data } \\
\hline $1977-$ & The Danish National Patient Registry & Comorbidity $^{\mathrm{a}}$ \\
\hline $1984-$ & The Danish Cancer Registry & Diagnosis, histology \\
\hline 1993- & The Danish In Vitro Fertilization Register & Help to achieve pregnancy with spouse \\
\hline 1995- & The Danish National Prescription Registry & Use of medication \\
\hline $1984-$ & The Danish Register of Causes of Death & Cause of death \\
\hline 2014 & The Danish Civil Registration System & Marital status, place of living, birthplace, migration \\
\hline $1984-$ & The Danish Pathology Register & Tumor characteristics \\
\hline
\end{tabular}

\section{DaTeCa-LATE}

\section{PROM}

2014-2016 Fatigue

Quality of life

Anxiety and depression

Psychological distress

Demographics

Alcohol and tobacco

Substance abuse history

Health

Exercise

Family history

Pain

Neurotoxicity

Infertility before and after testicular cancer diagnosis

Symptoms of testosterone deficiency and erectile dysfunction

Medical history and symptoms
Multiple fatigue inventory (MFI-20)

EORTC QLQ-C30

Hospital anxiety and depression scale (HADS)

Perceived stress scale (PSS)

Education level, occupation, income

Type, duration and frequency

Amphetamines, cocaine, heroin, hallucinogens, marijuana, barbiturates, ecstasy, steroids Self-rated, behaviors. Type and frequency in use of medication. Height, weight

Type, frequency, self-rated physical health

Medical diagnoses in first- and second-degree relatives

Localization, intensity

FACT/GOG-NTX subscale

Use of sperm bank, children, type and use of medical help

International Index of Erectile Dysfunction (IIEF-15)

Use of medication, diseases in relatives, respiratory symptoms 
The Danish in Vitro Fertilization Register provided information on help to achieve pregnancy (17), from the Danish National Prescription Registry knowledge of prescribed medications have been obtained (18), and by linkage to the Registry of Causes of Death we obtained the dates and causes of death (19).

\section{PATIENT REPORTED OUTCOME MEASURES (PROM)}

The abovementioned questionnaire contain PROMs concerning quality of life (EORTC QLQ-30) (20), fatigue (Multiple Fatigue Inventory) (21), symptoms of testosterone deficiency and erectile dysfunction (International Index of Erectile Dysfunction) (22), psychological distress [perceived stress scale (PSS)] (23), depression and anxiety (hospital anxiety and depression scale) (24), and neurotoxicity (FACT/GOG-NTX) (25). Additional PROM outcomes are education, occupation, income, alcohol, tobacco, drug use and abuse, self-rated health, physical activity, anthropometrics, pain, and infertility.

\section{BIOBANK}

A total of 430 TC patients treated with chemotherapy have contributed with DNA samples derived from sputum or blood in order to identify predictive genetic markers for long-term toxicities. Furthermore, in 2012, additionally 245 TC patients had provided serum, plasma and DNA samples for the Danish Cancer

TABLE 3 | Perceived stress scale (PSS), total scores.

\begin{tabular}{lccc}
\hline & $\begin{array}{c}\text { Testicular cancer } \\
\text { survivors }\end{array}$ & $\begin{array}{c}\text { Reference } \\
\text { population }\end{array}$ & P-Value \\
\hline PSS mean total score & 11.6 & 10.7 & $<0.001$ \\
SD & 6 & 7 & \\
No. & 2,545 & 69,438 & \\
\hline
\end{tabular}

PSS mean total score compared with independent t-test.
Biobank (26), and since then nearly all TC patients have provided samples for later analyses.

\section{PREVIOUS, ONGOING, AND PLANNED STUDIES}

We have previously reported that patients followed on surveillance are at no higher risk for a new primary cancer compared to the background population (3), while this is the case for patients treated with chemotherapy, RT, or MTOL for disseminated disease, who also have increased mortality compared to patients with stage I disease $(3,27)$. Furthermore, we have found that renal and pulmonary toxicity related to treatment is partly reversible $(28,29)$. Risk of late relapses is low in surveillance patients, who carries a good prognosis $(30,31)$. Additionally, we have shown that patients with preexisting Leydig cell dysfunction are at increased risk of testosterone deficiency following treatment (32-34).

A new finding from DaTeCa-LATE is that TCS have higher PSS scores than the reference population. This is illustrated in Table 3, where mean PSS scores were compared between TCS and the reference population with independent $t$-test. No cutoff values exist for PSS, but generally a score of 15 or above is considered as a high stress level (35). In Figure 3, TCSs PSS score was categorized in age groups and allocated into quartiles according to reference group quartile PSS scores. Confined to TCS $<65$ years of age we found a higher level of perceived stress compared to the reference population. In total, $16-19 \%$ of TCS $<65$ years of age had PSS scores in the lowest quartile, while $53-64 \%$ had PSS scores in the two highest quartiles.

To further elaborate on this primary analysis of PSS, we plan comparison of TCS level of perceived stress and lifestyle factors (physical activity, smoking, and alcohol consumption) with the reference population. In addition we will compare PSS scores of TCS with survivors of other cancer types.

Planned studies from DaTeCa-LATE include evaluation of quality of life and sexual function in bilateral TC as well as analysis of quality of life, education, psychiatric diseases and drug

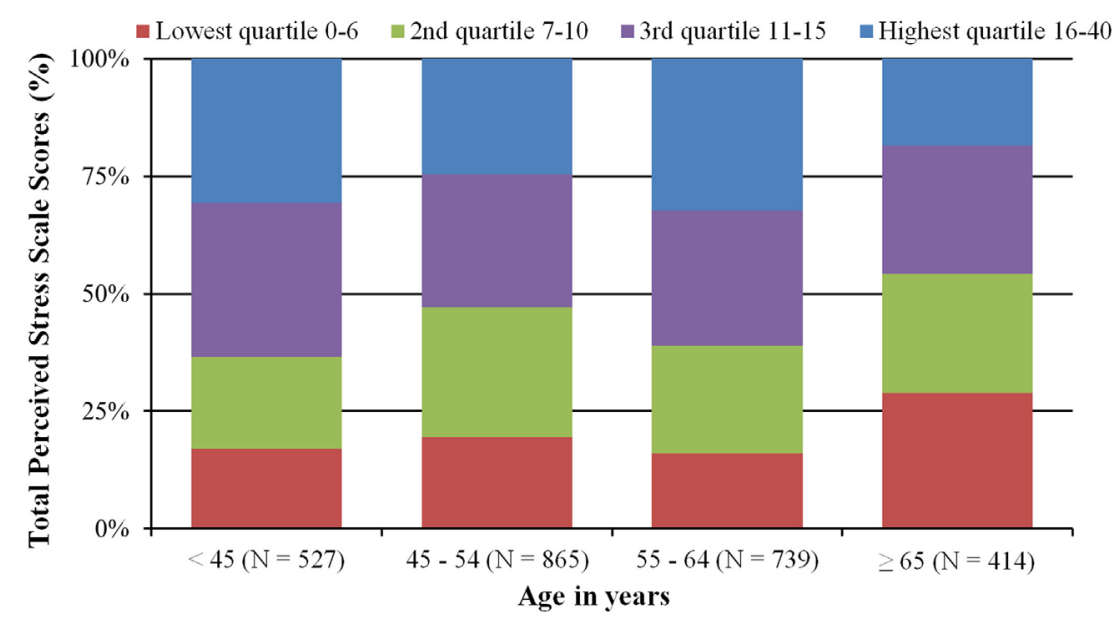

FIGURE 3 | Testicular cancer survivors perceived stress scale (PSS) scores categorized in age groups and allocated into quartiles according to reference group quartile PSS scores. 
abuse, fatigue, sexual function, and paternity rate stratified on treatment modality and compared with a non-cancerous reference population when applicable. In addition, genetic differences related to toxicity and more rarely explored late-effects will be investigated.

Statistical analyses will be performed using SPSS (SPSS, Chicago, IL, USA) and R software (R Core Development Team, Vienna, Austria).

We plan an additional follow-up survey of the cohort after 5-10 years as well as an extension adding more recently diagnosed cases of TC.

\section{WHAT ARE THE MAIN STRENGTHS AND WEAKNESSES?}

The Danish Testicular Cancer Late Treatment Effects Cohort is the largest cohort of TCS with a long observation period since diagnosis and treatment. The study is nationwide and population based which together with the long time since diagnosis leads to a high degree of reliability of the results obtained in various studies. The study includes a combination of an excessive number of clinical data, comprehensive PROM data, and access to various administrative register data established independently of the hypothesis under study. This type of data almost completely avoid the possibility that selection, information as well as recall bias influence the results, securing a high validity of the observations.

The treatment during the observation period has been nearly the same for all stages of TC and is in agreement with today's standard treatment. Patients responding to the questionnaire can be compared with non-responders and a reference population. The cohort can easily be extended to assess additional outcomes, or include new TC patients.

A possible limitation is the differences observed in age, marital status and treatment modality between responders and non-responders of the questionnaire. However, the absolute difference in age is negligible and the proportion of patients treated with surveillance, BEP and RT is representative of today's TC treatment pattern. Thus, we do not expect that these differences will influence the interpretation of PROM data. The difference in marital status with more responders than non-responders living in a paired relation is in accordance with the findings of other similar studies (36), and the finding can be problematic in special

\section{REFERENCES}

1. Fitzmaurice C, Dicker D, Pain A, Hamavid H, Moradi-Lakeh M, MacIntyre MF, et al. The global burden of cancer 2013. JAMA Oncol (2015) 1(4):505-27. doi:10.1001/jamaoncol.2015.0735

2. Engholm G, FerlayJ, Christensen N, Hansen HL, Hertzum-Larsen R, Johannesen TB, et al. NORDCAN: Cancer Incidence, Mortality, Prevalence and Survival in the Nordic Countries, Version 8.0 (20.12.2017). Association of the Nordic Cancer Registries. Danish Cancer Society (2017). Available from: http://www-dep.iarc. fr/NORDCAN/English/StatsFact.asp? cancer $=271 \&$ country $=208$

3. Kier MG, Hansen MK, Lauritsen J, Mortensen MS, Bandak M, Agerbaek M, et al. Second malignant neoplasms and cause of death in patients with germ cell cancer: a Danish nationwide cohort study. JAMA Oncol (2016) 2(12):1624-7. doi:10.1001/jamaoncol.2016.3651 cases, but overall we find that this cohort of TCSs is representative for TCSs in Denmark.

As $>95 \%$ of TC patients become long-term survivors, survivor bias is generally not a limitation. However, as the mortality is high in the MTOL group, interpretation of especially PROM data among these patients should be done with caution, as they might represent a highly selected group of TC who have survived several lines of TC treatment. Despite the fact that TC is a rare tumor implying that some rare outcomes would be difficult to investigate, the advantages of the information in this large cohort of TC provide a data set that is highly interesting for future studies.

\section{CAN I GET HOLD OF THE DATA? WHERE CAN I FIND OUT MORE?}

The DaTeCa-LATE steering group welcomes collaboration and the interest of national and international colleagues. External researchers can get access to data by a collaboration agreement with the DaTeCa-LATE steering group. For more information on how to apply, please contact Professor Gedske Daugaard, kirsten. gedske.daugaard@regionh.dk.

\section{ETHICS STATEMENT}

The regional ethical committee of the Capital Region of Denmark approved the study (file number, H-2-2012-044). The study was carried out in accordance with their recommendations. All subjects gave written informed consent in accordance with the Declaration of Helsinki.

\section{AUTHOR CONTRIBUTIONS}

MK, MB, JL, CJ, and GD contributed to data collection, data analyses, and drafting the manuscript. All authors contributed to the writing of this manuscript. MK, MB, JL, JS, NJ, MA, NH, and GD contributed to data collection and data quality. All authors read and approved the final manuscript.

\section{FUNDING}

This work was supported in part by The Danish Cancer Society and the Preben and Anna Simonsen Foundation.

4. Travis LB, Curtis RE, Storm H, Hall P, Holowaty E, Van Leeuwen FE, et al Risk of second malignant neoplasms among long-term survivors of testicular cancer. J Natl Cancer Inst (1997) 89(19):1429-39. doi:10.1093/jnci/89.19.1429

5. Haugnes HS, Aass N, Fosså SD, Dahl O, Klepp O, Wist EA, et al. Components of the metabolic syndrome in long-term survivors of testicular cancer. Ann Oncol (2007) 18(2):241-8. doi:10.1093/annonc/mdl372

6. Huddart RA, Norman A, Shahidi M, Horwich A, Coward D, Nicholls J et al. Cardiovascular disease as a long-term complication of treatment for testicular cancer. J Clin Oncol (2003) 21(8):1513-23. doi:10.1200/JCO.2003. 04.173

7. Sprauten M, Darrah TH, Peterson DR, Campbell ME, Hannigan RE, Cvancarova $\mathrm{M}$, et al. Impact of long-term serum platinum concentrations on neuro- and ototoxicity in cisplatin-treated survivors of testicular cancer. J Clin Oncol (2012) 30(3):300-7. doi:10.1200/JCO.2011.37.4025 
8. Nazareth I, Lewin J, King M. Sexual dysfunction after treatment for testicular cancer: a systematic review. J Psychosom Res (2001) 51(6):735-43. doi:10.1016/ S0022-3999(01)00282-3

9. Dahl AA, Haaland CF, Mykletun A, Bremnes R, Dahl O, Klepp O, et al. Study of anxiety disorder and depression in long-term survivors of testicular cancer. J Clin Oncol (2005) 23(10):2389-95. doi:10.1200/JCO.2005.05.061

10. Mortensen MS, Lauritsen J, Gundgaard MG, Agerbaek M, Holm NV, Christensen IJ, et al. A nationwide cohort study of stage I seminoma patients followed on a surveillance program. Eur Urol (2014) 66(6):1172-8. doi:10.1016/j.eururo.2014.07.001

11. Daugaard G, Kier M, Bandak M, Mortensen MS, Larsson H, Søgaard M, et al. The Danish testicular cancer database. Clin Epidemiol (2016) Volume 8:703-7. doi:10.2147/CLEP.S99493

12. Sundhedsstyrelsen. Den Nationale Sundhedsprofil 2013 - Hvordan har $d u$ det? [The Danish National Health Profile 2013 - How are you?]. Copenhagen: Danish Health Authority (2014). Available from: www.danskernessundhed.dk

13. Pedersen CB. The Danish civil registration system. Scand J Public Health (2011) 39(7 Suppl):22-5. doi:10.1177/1403494810387965

14. Schmidt M, Schmidt SA, Sandegaard JL, Ehrenstein V, Pedersen L, Sørensen HT, et al. The Danish national patient registry: a review of content, data quality, and research potential. Clin Epidemiol (2015) 7:449-90. doi:10.2147/CLEP. S91125

15. Gjerstorff ML. The Danish cancer registry. Scand J Public Health (2011) 39(7 Suppl):42-5. doi:10.1177/1403494810393562

16. Bjerregaard B, Larsen OB. The Danish pathology register. Scand JPublic Health (2011) 39(7_suppl):72-4. doi:10.1177/1403494810393563

17. Andersen AN, Westergaard HB, Olsen J. The Danish in vitro fertilisation (IVF) register. Dan Med Bull (1999) 46(4):357-60.

18. Kildemoes HW, Sorensen HT, Hallas J. The Danish national prescription registry. Scand J Public Health (2011) 39(7 Suppl):38-41. doi:10.1177/ 1403494810394717

19. Helweg-Larsen K. The Danish register of causes of death. Scand J Public Health (2011) 39(7 Suppl):26-9. doi:10.1177/1403494811399958

20. Kaasa S, Bjordal K, Aaronson N, Moum T, Wist E, Hagen S, et al. The EORTC core quality of life questionnaire (QLQ-C30): validity and reliability when analysed with patients treated with palliative radiotherapy. Eur JCancer (1995) 31A(13-14):2260-3. doi:10.1016/0959-8049(95)00296-0

21. Smets EMA, Garssen B, Bonke B, De Haes JCJM. The multidimensional fatigue inventory (Mfi) psychometric qualities of an instrument to assess fatigue. J Psychosom Res (1995) 39(5):315-25. doi:10.1016/0022-3999(94)00125-O

22. Rosen RC, Riley A, Wagner G, Osterloh IH, Kirkpatrick J, Mishra A. The international index of erectile function (IIEF): a multidimensional scale for assessment of erectile dysfunction. Urology (1997) 49(6):822-30. doi:10.1016/ S0090-4295(97)00238-0

23. Cohen S, Kamarck T, Mermelstein R. A global measure of perceived stress. J Health Soc Behav (1983) 24(4):385-96. doi:10.2307/2136404

24. Zigmond AS, Snaith RP. The hospital anxiety and depression scale. Acta Psychiatr Scand (1983) 67(6):361-70. doi:10.1111/j.1600-0447.1983. tb09716.x

25. Huang HQ, Brady MF, Cella D, Fleming G, Mackey D. Validation and reduction of FACT/GOG-Ntx subscale for platinum/paclitaxel-induced neurologic symptoms: a gynecologic oncology group study. Int J Gynecol Cancer (2007) 17(2):387-93. doi:10.1111/j.1525-1438.2007.00794.x

26. Modin C, Bjerregaard B, Orntoft T, Hogdall E. [Establishing the Danish CancerBiobank]. Ugeskr Laeger (2010) 172(19):1446-50.

27. Lauritsen J, Kier MGG, Mortensen MS, Bandak M, Gupta R, Holm NV, et al. Germ cell cancer and multiple relapses: toxicity and survival. J Clin Oncol (2015) 33(28):3116-23. doi:10.1200/JCO.2014.60.1310

28. Lauritsen J, Kier MGG, Bandak M, Mortensen MS, Thomsen FB, Mortensen J, et al. Pulmonary function in patients with germ cell cancer treated with bleomycin, etoposide, and cisplatin. J Clin Oncol (2016) 34(13):1492-9. doi:10.1200/ JCO.2015.64.8451

29. Lauritsen J, Mortensen MS, Kier MGG, Christensen IJ, Agerbaek M, Gupta R, et al. Renal impairment and late toxicity in germ-cell cancer survivors. Ann Oncol (2015) 26(1):173-8. doi:10.1093/annonc/mdu506

30. Mortensen MS, Lauritsen J, Kier MGG, Bandak M, Appelt AL, Agerbaek M, et al. Late relapses in stage I testicular cancer patients on surveillance. Eur Urol (2016) 70(2):365-71. doi:10.1016/j.eururo.2016.03.016

31. Mortensen MS, Bandak M, Kier MGG, Lauritsen J, Agerbaek M, Holm NV, et al. Surveillance versus adjuvant radiotherapy for patients with high-risk stage I seminoma. Cancer (2017) 123(7):1212-8. doi:10.1002/cncr.30458

32. Bandak M, Jørgensen N, Juul A, Vogelius IRR, Lauritsen J, Kier MGG, et al. Testosterone deficiency in testicular cancer survivors - a systematic review and meta-analysis. Andrology (2016) 4(3):382-8. doi:10.1111/andr.12177

33. Bandak M, Jørgensen N, Juul A, Lauritsen J, Kier MGG, Mortensen MS, et al. Longitudinal changes in serum levels of testosterone and luteinizing hormone in testicular cancer patients after orchiectomy alone or bleomycin, etoposide, and cisplatin. Eur Urol Focus (2016) 2016:1-8. doi:10.1016/j.euf.2016.11.018

34. Bandak M, Jørgensen N, Juul A, Lauritsen J, Gundgaard Kier MG, Mortensen MS, et al. Preorchiectomy leydig cell dysfunction in patients with testicular cancer. Clin Genitourin Cancer (2016) 15(1):e37-43. doi:10.1016/j.clgc.2016. 07.006

35. Nielsen L, Curtis T, Kristensen TS, Rod Nielsen N. What characterizes persons with high levels of perceived stress in Denmark? A national representative study. Scand J Public Health (2008) 36(4):369-79. doi:10.1177/ 1403494807088456

36. Tolonen H, Helakorpi S, Talala K, Helasoja V, Martelin T, Prättälä R. 25-year trends and socio-demographic differences in response rates: Finnish adult health behaviour survey. Eur J Epidemiol (2006) 21(6):409-15. doi:10.1007/ s10654-006-9019-8

Conflict of Interest Statement: The authors declare that the research was conducted in the absence of any commercial or financial relationships that could be construed as a potential conflict of interest.

Copyright (c) 2018 Kreiberg, Bandak, Lauritsen, Skøtt, Johansen, Agerbaek, Holm, Johansen and Daugaard. This is an open-access article distributed under the terms of the Creative Commons Attribution License (CC BY). The use, distribution or reproduction in other forums is permitted, provided the original author $(s)$ and the copyright owner are credited and that the original publication in this journal is cited, in accordance with accepted academic practice. No use, distribution or reproduction is permitted which does not comply with these terms. 